\title{
Elites regimentales y pecheros: prácticas coactivas y resistencias en el concejo de Ávila
}

Regimental elites and the commoners: coercive practices and resistances in Avila council.

Tamara Somoza

Universidad de Buenos Aires, Argentina

tam.smz@gmail.com

\section{RESUMEN:}

Las elites regimentales de Ávila llevan a cabo una serie de prácticas coactivas sobre los pecheros que afectan de manera significativa sus condiciones de reproducción: usurpan sus tierras y términos comunales, imponen prendas y tributos, obstaculizan su accionar político dentro del concejo, entre otras. El presente artículo se propone arribar a una caracterización de estas prácticas; a la vez que identificar sus efectos y las distintas resistencias que elabora la comunidad de campesinos.

Palabras Clave: Elites regimentales, Pecheros, Ávila, Prácticas coactivas, Resistencias.

\section{Abstract:}

Regimental elites of Avila carry out several coercive practices on the commoners that affect their reproduction conditions: they usurp their lands and communal terms, impose tributes and obstruct their political action in the council.

This article intends to arrive at a characterization of these practices; and to identify their effects and the different resistances developed by the peasant community.

KEYWORDS: Regimental elites, Commoners, Avila, Coercive practices, Resistances.

\section{INTRODUCCIÓN}

Las elites regimentales del concejo de Ávila, aquellas encargadas de ejecutar el realengo transferido, llevan a cabo una serie de prácticas coactivas sobre los pecheros, tales como la usurpación de sus tierras y bienes comunales, la imposición de prendas y tributos y la restricción u obstaculización de su propia organización política. Los protagonistas de estas acciones coercitivas constituyen una minoría de propietarios destacados que en muchos casos se desempeñan como oficiales concejiles y exhiben posiciones preeminentes en la comunidad.

Este artículo tiene por objetivo caracterizar las diversas presiones que impone este sector de privilegiados, a la vez que se propone el análisis del impacto de estas prácticas y de las resistencias que las mismas generan entre los tributarios, en la medida en que afectan de manera significativa las condiciones de reproducción de los contribuyentes. En este sentido, el carácter realengo del caso seleccionado nos permite establecer un diálogo crítico con los planteos historiográficos dominantes que contrastan las condiciones de vida de los campesinos de acuerdo al encuadramiento jurisdiccional en el que se encuentren: mientras que el realengo sería un ámbito favorable, el señorío privado constituiría un marco comparativamente hostil para los hogares pecheros (Foronda y Carrasco Manchado, 2008; Lorenzo Cadarso, 1996; Monsalvo Antón, 2001, 2010). Por el contrario, el estudio de las prácticas efectivas de los agentes dentro del concejo abulense señala la necesidad de matizar este esquema dual. 
Por otra parte, dado que el siglo XV constituye el escenario en el que situamos esta investigación; las circunstancias particulares de esta centuria obligan a considerar especialmente el fortalecimiento de los núcleos señoriales menores detraídos de la jurisdicción regia.

\section{Problemas en torno de las prácticas coactivas de las elites urbanas y RESISTENCIAS CAMPESINAS}

Las relaciones que establecen las elites villanas y los pecheros dentro del realengo han sido objeto de estudio privilegiado. José María Monsalvo Antón, referencia insoslayable en esta cuestión, advierte el vínculo conflictivo entre ambos actores "basado en antagonismos verticales" (Monsalvo Antón, 2001: 108). Luego del período de repoblación de la Península Ibérica, a partir del siglo XIII, la sociedad castellana se encuentra dividida en dos grupos contrapuestos: los pecheros, que conforman la abrumadora mayoría de la población, y los caballeros villanos que, por privilegios sucesivos otorgados por la monarquía, gozan de la exención impositiva de sus propiedades y clientelas y acceden posteriormente al control del poder urbano. Estas diferencias iniciales cristalizan a partir de la reforma municipal impulsada por Alfonso XI que instaura el regimiento como órgano de gobierno cerrado, restringido y excluyente en todas las ciudades y villas del reino. ${ }^{1}$

La caracterización de esta minoría privilegiada remite a la vasta discusión sobre la identidad social de la caballería villana: ¿son señores feudales?, o en caso contrario, ¿qué los diferencia de ellos? La superación definitiva del paradigma institucionalista implicó el abandono de la identificación de los caballeros con un sector popular que convive con los productores libres, en un contexto de fluida movilidad social y completamente ajeno a la clase de poder (Sánchez Albornoz, 1956). Por el contario, las posteriores reflexiones de los años ' $80^{2}$ coinciden en destacar su asimilación a la clase señorial (Barrios García, 1983-1984; Mínguez Fernández, 1982; Clemente Ramos, 1991). Aunque con diferentes matices, estas interpretaciones sostienen la existencia de un poder político -de ban-individual ejercido por los caballeros extremeños.

Sin embargo, actualmente la visión historiográfica predominante considera que la caballería villana ejerce como estamento la delegación de la jurisdicción regia sobre las aldeas circundantes al concejo que encabezan (Astarita, 1994; Estepa Díez, 1984; Monsalvo Antón, 1986). Esto significa que el poder de ban no lo ejerce individualmente cada caballero villano -pese al desarrollo de trayectorias individuales en las que acceden a la titularidad de señoríos- ${ }^{3}$, sino que es delegado en el conjunto del estamento privilegiado al que pertenece. Carlos Astarita destaca que el presupuesto de esta singular condición es que los miembros de la caballería dispongan de recursos o mecanismos de reproducción social que no dependan del poder político individual. En este sentido, para este autor la reproducción de los caballeros villanos está basada en la propiedad de tierras y ganado y en la explotación de mano de obra asalariada. En definitiva, se trata de propietarios privados que en la instancia corporativa concejil ejercen colectivamente el poder, delegado por el monarca, pero cuya reproducción material se supedita a su posición como propietarios. ${ }^{4}$ Los intereses patrimoniales de estos grupos se presentan como la determinación principal de las conductas que despliegan sobre el territorio y su población.

Desde esta perspectiva, Monsalvo Antón identifica en los caballeros villanos una serie de acciones sobre los pecheros que no solo afectan negativamente a las economías campesinas, sino que contradicen abiertamente tanto las normas locales como las disposiciones regias. La usurpación de términos comunales constituye, precisamente, un ejemplo de estas prácticas a las que particularmente este autor dedica su atención.

Como es de amplio conocimiento, el fenómeno de las apropiaciones de bienes colectivos constituye un proceso generalizado en toda la corona castellana. En numerosas ocasiones, los caballeros usurpadores no poseen títulos de propiedad y actúan por medio de la fuerza, contrarrazón y derecho, movilizando una red de hombres armados que integran sus respectivas clientelas. ${ }^{5}$ El estudio de los abundantes litigios 
que desencadenan estas masivas apropiaciones permite calificar a sus protagonistas como "violentos", “prepotentes” y “arrogantes” (Monsalvo Antón, 2001).

Las usurpaciones de tierras van acompañadas de toda una serie de acciones compulsivas entre las que podemos mencionar el desplazamiento de poblaciones con el fin de reubicarlas en un nuevo asentamiento, la instalación de renteros en las tierras ocupadas, el despoblamiento, los intentos de ampliación patrimonial de algunos señores a costa de la absorción de aldeas próximas a sus señoríos, la exigencia de tributos o de prendas -entre ellas la toma de ganado-, el acaparamiento de propiedades, la destrucción de bienes de los campesinos, las intimidaciones, amenazas y el uso múltiple de la fuerza física. Al respecto, Monsalvo Antón alude al concepto de "violencias rurales" (Monsalvo Antón, 2012) para referirse a las diversas coerciones que los miembros del patriciado urbano despliegan sobre los pecheros del realengo, aún sin ser señores de vasallos propiamente dichos. Las violencias se originan "no tanto de la actuación señorial en sí -es decir, los típicos abusos señoriales, tan frecuentes en otros sitios- sino de los intentos previos para conseguirla" (Monsalvo Antón, 2012: 419). Si bien este proceso coactivo puede dar lugar a una posterior señorialización -en la medida en que obtengan el favor regio-, no es éste su obligado desenlace. De este modo, esta fenomenología "nacía en el propio realengo, venía favorecida por los perversos efectos sociales de la propiedad privilegiada y se concentraba en los abusos de los grandes propietarios urbanos como herederos principales en un lugar o como dueños de términos redondos, pero que no eran señoríos" (Monsalvo Antón, 2012: 420).

En este sentido, la distinción entre las acciones de las elites concejiles y los abusos propios de los señores feudales enfatiza la diferenciación de las minorías urbanas respecto de la clase señorial que sostiene el autor. ${ }^{6}$ De allí que al describir las prácticas de las elites aluda a la "imposición de cargas de tipo paraseñorial rentas por arar, prestaciones de tipo laboral...” (Monsalvo Antón, 2012: 421). ${ }^{7}$ Dentro de esta formulación, Monsalvo Antón postula que "no hay que confundir los efectos de la propiedad con los efectos del señorío" (Monsalvo Antón, 1997: 320), motivo por el cual opone de manera categórica el concepto de "forma señorial de baja intensidad" al de la "gran propiedad privilegiada, pero no señorío" (Monsalvo Antón, 1992b: $85)^{8}$

Ahora bien, ¿̇resulta necesaria esta distinción tajante entre propietarios privilegiados y señores de hecho? En un artículo de publicación reciente, Octavio Colombo destaca que las usurpaciones no se definen por la mera ocupación del espacio y la ampliación de las propiedades privilegiadas de los caballeros, sino que implican distintas formas de sometimiento de los aldeanos. De esta manera, las usurpaciones "están teñidas de esa cualidad feudal en el que el dominio de la tierra se identifica con el dominio de los productores" (Colombo, 2018: 182). Los caballeros ejercen un poder político y jurisdiccional sobre las aldeas que dominan, por más que no sean sus señores legales y que las mismas sigan perteneciendo al realengo. Los caballeros imponen obediencia y, de esta manera, se pueden apropiar de tierras y tributos: "se comportan con los campesinos conmo sy fuesen sus vasallos" (Colombo, 2018: 176). Existe, por tanto, cierta contradicción entre lo que los caballeros hacen (actúan como señores) y lo que los caballeros son en realidad (delegados del poder regio y no poseedores de poder de ban individual). ${ }^{9}$ Los caballeros, por tanto, imponen obediencia y exigen renta; acciones que los convierten en señores de facto.

En este sentido, Clara López Benito afirma que la apropiación de jurisdicciones se relaciona estrechamente con la usurpación de tierras. A los beneficios que reporta la apropiación de un suelo, se suman "los derechos que todo señor tenía sobre sus vasallos y de los que obtenía por la ejecución de justicia” (López Benito, 1983: 173). Los caballeros asumen efectivamente el poder político-jurisdiccional sobre esos espacios. Asimismo, Carmelo Luis López refiere a la señorialización "de facto" por parte de las oligarquías urbanas (Luis López, 1993) y José Antonio Jara Fuente apela al concepto de "preseñorialización” para dar cuenta de esta situación (Jara Fuente, 2002-2003: 103).

En virtud de ello, María Ángeles Martín Romera destaca la existencia de lazos informales que es preciso recuperar para comprender la realidad del ejercicio del poder urbano. Así pues, en la sociedad medieval las prácticas informales son parte estructurante del poder; de modo que pese a la ausencia de 
una concesión señorial por parte de la monarquía, el señorío en tanto relación de dominación emerge de todas formas. En este sentido, coincidimos en que la diferenciación entre prácticas formales e informales resulta "completamente artificial e inexistente en la sociedad medieval que las comprendía como un todo indisoluble" (Martín Romera, 2014: 159).

Aun así, estas prácticas no configuran meras violaciones de un orden legal, producto de las características violentas y de la arrogancia de las elites. En el caso de las usurpaciones, Colombo señala que las mismas conforman "la forma natural de la reproducción ampliada de los caballeros" (Colombo, 2018: 203) y no simples desviaciones de la norma. A través de estas conductas, las elites intentan conjugar su carácter de propietarios con la disposición del poder de mando, aspecto que los convierte en propietarios plenos en un sentido feudal.

Llegados a este punto, podemos identificar dos interpretaciones historiográficas respecto del significado de las actuaciones coercitivas de las elites: por un lado, quienes perciben en ellas acciones violentas derivadas de la condición de propietarios privilegiados, procurando especialmente separarlas de los abusos de tipo señoriales; y por otro, quienes las reconocen como conductas esencialmente señoriales.

Ahora bien, ¿cómo responden los campesinos ante estas prácticas coactivas/señorializadoras de los poderosos caballeros? ${ }^{10} \mathrm{Si}$ bien la historiografía en general se ha centrado en la reacción institucional de los grandes concejos de realengo frente a las iniciativas señorializadoras de la alta nobleza, especialmente en el período Trastámara (Mínguez Fernández, 1980; Monsalvo Antón, 2015-2016; Muñoz Gómez, 2009); ${ }^{11}$ actualmente existen distintos trabajos sobre las resistencias a la señorialización protagonizadas por los propios tributarios (García Oliva, 2018; Monsalvo Antón, 2012), generalmente desarrolladas a partir de canales legales. $^{12}$

El análisis de María Dolores García Oliva para el concejo de Mirabel resulta significativo. Si bien se trata de una concesión regia a un miembro de la alta nobleza, Francisco de Estúñiga, es interesante el énfasis que pone la autora en las condiciones materiales de reproducción de los productores sometidos a un nuevo marco de relaciones. La ausencia de resistencias de los campesinos ante el nuevo señor ${ }^{13}$ pareciera obedecer a la entrega de unas tierras baldías a censo perpetuo, que incidiría en que las condiciones de vida resultaran favorables. Sin embargo, el conflicto se origina cuando se ven alteradas las prácticas cotidianas de las unidades domésticas y se atenta contra sus condiciones de reproducción. Así, al otorgarse el señorío a la viuda de su titular original, quien intenta modificar el contrato de censo perjudicando los derechos campesinos sobre las tierras, los pecheros reaccionan elevando sus quejas ante los reyes.

En este punto consideramos que existe una estrecha vinculación entre el estallido de los conflictos y la perturbación de las condiciones de vida de los campesinos. En este sentido, no sería el mero cambio de titularidad jurisdiccional el que motiva el malestar, sino los efectos concretos que éste pudiera tener sobre las prácticas cotidianas de los pecheros. Este aspecto se aprecia particularmente en las luchas de los tributarios contra las estrategias patrimoniales de los caballeros, especialmente de aquellos que ocupan cargos principales dentro de los concejos de realengo (Luchía, 2016).

Los reclamos aldeanos son amplios; no surgen solamente por cuestiones que afectan sus economías, sino también por razones de orden político, especialmente cuando sus formas de organización comunitaria son violentadas. En lo que sigue nos centraremos en las demandas que elevan los tributarios frente a la violencia que ejercen las elites regimentales de Ávila en su carácter de señores de facto de ciertas aldeas, violencia que inquieta no sólo sus intereses productivos, sino también su estructuración política. En este sentido, entendemos el concepto de reproducción de manera amplia, incluyendo en él las propias condiciones de autonomía organizativa (Bourdieu, 2006). Con esto pretendemos trascender los abordajes reduccionistas que vinculan estrechamente la noción de reproducción a las meras circunstancias "económicas", para dar cuenta, como se pretende en este artículo, de las condiciones de vida en un sentido más vasto. 


\section{Están EN TOdo ocupados y tomados ASÝ a LA DICHA . IBDAT de ÁUILA EN LA JUREDIÇIÓN COMO EN LOS TÉRMINOS}

La extensa presentación del escenario historiográfico que desarrollamos en el precedente apartado nos permite inscribir el estudio de caso que aquí proponemos dentro de los principales problemas que son objeto de debate en la actualidad.

Ávila sobresale dentro del concierto de ciudades castellanas por el poder que alcanzan los caballeros regimentales: no sólo ocupan los principales cargos municipales, sino que algunos de ellos son titulares de pequeños núcleos señoriales. Por este motivo Monsalvo Antón los denomina "caballeros-señores" (Monsalvo Antón, 2001: 100); segmento entre los que se destacan varias ramas de los Dávila, con presencia en el regimiento a lo largo de varias generaciones (Monsalvo Antón, 2001, 2010). ${ }^{14}$

En este sentido, la vasta documentación de este concejo arroja una copiosa información sobre la acción coactiva de las elites del regimiento, especialmente la que despliegan sobre los pecheros de las aldeas. El accionar de Pedro Dávila constituye un ejemplo significativo. Se trata del usurpador más reconocido y temido por los aldeanos, ${ }^{15}$ además de regidor ${ }^{16}$ y titular de los pequeños señoríos de Villafranca y Las Navas. Paralelamente, ejecuta de manera sistemática una serie de prácticas coactivas en los distintos lugares pertenecientes a la jurisdicción de Ávila: Navalmoral, El Quintanar, El Helipar, Burgohondo, entre otros. La actuación de Pedro Dávila, que parece no tener límite, ocasiona numerosos conflictos con la comunidad pechera, que a pesar del temor que inspira a los aldeanos, logra encauzar judicialmente sus demandas y denunciarlo ante las instancias provistas por la Corona. Veamos algunas de las prácticas coercitivas que son objeto de reproche y las respuestas de los pecheros frente a las mismas.

Las largas reyertas judiciales por el término de Navalmoral acaecidas a lo largo del siglo XV y principios del XVI entre los pecheros abulenses y el linaje de los Dávila conforman un escenario representativo. Particularmente, Pedro es descripto como apropiador ilegítimo, violento, responsable de cometer acciones fraudulentas e incluso temerarias que llegan entre otras consecuencias a la imposición de tributos. Tanto Pedro Dávila como los de su casa "syenpre de fecho avían tomado e ocupado, tomavan e ocupavan de la dicha çibdad de Ávila e de sus términos muchas partes, tierras e alixares e abrevaderos e pastos comunes que eran e son vezinos e pasto común de la dicha çibdad e de su tierra e pueblos" (Luis López, 1995, 1: 13). Aquí es denunciada una apropiación patrimonial: la toma, la ocupación de ciertos términos y tierras comunes. Ahora bien, ¿qué implica esta apropiación? O, mejor dicho, ¿qué implican los verbos tomar y ocupar?

En primer lugar, la ocupación del espacio importa la toma de prendas a sus usufructuarios consuetudinarios. Si bien formalmente los soberanos fallan a favor de Ávila y su tierra en numerosas ocasiones, ordenando que se respeten las sentencias y las cartas pasadas -que se remontan a los tiempos de Juan II y Enrique IV y muchas de ellas habían dado lugar a las restituciones correspondientes- ${ }^{17}$ para 1477 el apropiador continúa imponiendo prendas en el término: "esto non enbargante, vuestro alcayde de Las Navas e vasallos...Prendan a los vezinos e moradores" (Martín Rodríguez, 1995, 51: 125). Es así que en 1489 el procurador pechero remarca la legítima jurisdicción del concejo de Ávila sobre los términos en disputa, solicita la restitución de los bienes y la liberación de las cargas señoriales, imposiciones o agravios que pesan sobre los tributarios de manera ilegítima y forzosa (Casado Quintanilla, 1999,356: 90).

Las usurpaciones no sólo expresan objetivos patrimoniales, sino que fundamentalmente tienen por fin el dominio y el control de población, implicando la apropiación de atribuciones jurisdiccionales. En este sentido, el procurador de los pecheros señala que Navalmoral "con los otros lugares de su con\#ejo están en todo ocupados y tomados asý a la dicha çibdat de Áuila en la juredi\#ión como en los términos” (Casado Quintanilla, 1999, 356: 78). ${ }^{18}$ Justamente, la llegada de Álvaro de Santiesteban, corregidor y juez pesquisidor para la recuperación de términos de Ávila, responde a la necesidad de 
"cobrar la jurediçión que deste lugar pertenesía a su justiçia e para restituyr a la dicha çibdat de Áuila en los términos e lugares, prados e pastos e abreuaderos que le estavan ocupados e para tener los vezinos deste lugar por vasallos de sus altezas e de la jurediçión de la dicha çibdat de Áuila"(Casado Quintanilla, 1999, 356: 78).

La ocupación de tierras, como vemos va acompañada de la usurpación de la jurisdicción y del ejercicio del poder político.

Ante la presencia de Santiesteban en Navalmoral, distintos testigos señalan que fueron obligados por Pedro Dávila y Juan de Cogollos, su mayordomo, a declarar que las tierras de Navalmoral le pertenecen a Pedro por haberlas comprado (Casado Quintanilla, 1999, 356: 87-90). El testimonio de Juan Muñoz indica que "sabe, y segund dirán otros viejos, cómo él no conpró nada de todo esto que tenía ocupado, syno poca cosa y de mala ventura" (Casado Quintanilla, 1999, 356: 83). ${ }^{19}$ El padre de Muñoz, asimismo, ya había padecido las acciones lesivas sobre los suelos y recursos, así como las imposiciones de prendas por parte de Diego de Ávila, padre de Pedro. Ante esto, Muñoz le había preguntado a su progenitor: "porque no se avían ydo a quexar al rey" (Casado Quintanilla, 1999,356: 84). La respuesta deja entrever los vínculos de los usurpadores con las instancias judiciales: "a este tienpo no tenían rey que les hiziese justi\#ia syno tal como el dotor o como Pedro Dáuila o como estos caualleros que hazían lo que querían y que los cuitados de los labradores avían de sufrir todo el mal que les hazían" (Casado Quintanilla, 1999,356: 84). ${ }^{20}$

La jurisdicción perteneciente al concejo de Ávila y, en última instancia, a los soberanos, es violentada por Pedro Dávila. En este sentido, Juan Muñoz hace referencia al cobro indebido de rentas por parte del caballero en tiempos de su padre, a quien refiere haberle cuestionado: "por qué le davan renta por lo que era del rey e suyo propio de los vezinos” (Casado Quintanilla, 1999,356: 84). El miedo a las represalias de los Dávila explica la pasividad ante estas acciones (Casado Quintanilla, 1999,356: 84). El poder de estos personajes excede la mera fortaleza individual para potenciarse a partir de la trama de relaciones que los vincula con la instancia política local.

En febrero de 1490 los procuradores del concejo de Navalmoral, Gil Fernández y Andrés García, solicitan la devolución de los bienes y la liberación de las cargas señoriales, imposiciones o agravios que pesan sobre los tributarios "syn justo título e por fuer\#a e contra su voluntad" (Canales Sánchez, 1996, 3, 1490: 14). Pese a que Santiesteban ya había adjudicado a Navalmoral la posesión de sus términos y dispuesto que sus pobladores no paguen las nuevas cargas, Navalmoral no encuentra justicia. La intervención de los Reyes Católicos instando al juez a ejecutar las sentencias de acuerdo a la ley de Toledo, ${ }^{21}$ no alcanza para frenar los atropellos del caballero.

Santiesteban también interviene en la restitución de las tierras del concejo aldeano de Burgohondo, donde Pedro tiene ocupados otros términos. ${ }^{22}$ Nuevamente Dávila vulnera los límites, desatendiendo las disposiciones regias. ${ }^{23}$ En 1490 el procurador de Pedro se lamenta ante los Reyes Católicos por las resoluciones judiciales en los concejos de Navalmoral y Burgohondo: "adjudicando en efecto los bienes propios suyos a la dicha çibdad e su tierra e declarándolos ser comunes, e mandando que por ellos non levasen rentas nin tributos algunos" (Canales Sánchez, 1996, 95: 209). La defensa del apropiador reconoce entonces que la ocupación implica la imposición de rentas y tributos. No se trata solo de la tierra, sino del poder sobre las personas.

En el término del Helipar también se da una situación similar. Santiesteban había emprendido una intensa labor para restituir el término a la comunidad; sin embargo, su activa disposición no alcanza el éxito. En la declaración de Juan Velázquez de Ávila, procurador de Pedro, que apela los "mandamientos dados por el liçençiado de Santystevan” (Luis López, 1995, 1: 27-28) argumenta que el linaje posee inmemorialmente el lugar "quieta e paçíficamente" (Luis López, 1995, 1: 28), con los títulos correspondientes para "defender e prendar a los que syn su liçença e consentimiento entrasen en los dichos términos a paçer las yervas e bever las aguas e roçar e arar e cortar e caçar e fazer otros qualesquier abtos" (Luis López, 1995, 1: 29). El pasaje 
resulta significativo en la medida en que establece una igualación entre la posesión del suelo y la acción de prendar a los hombres.

Son diversas las modalidades de usurpación de los Dávila. En algunos casos avanzan sobre los espacios linderos a sus legítimas posesiones, como ocurre en la dehesa de Navalsalse, hasta llegar a Navalmoral: "fue tomando mucho más término de lo que la dicha dehesa tenýa, e lo juntaron con ella" (Canales Sánchez, 1996, 8: 22). Santiesteban, motivado por una petición aldeana, ya había señalado los límites del término con la colocación de mojones. ${ }^{24}$ Sin embargo, la voluntad regia no fue suficiente para impedir el avance del caballero sobre los términos comunes, ya que los Reyes Católicos vuelven a ordenar al corregidor que realice esta tarea "por manera que el dicho Pedro de Ávila non tome más término con la dicha dehesa de lo que asý le pertenesçe e deva aver de derecho" (Canales Sánchez, 1996, 8: 22).

El litigio continúa a principios del siglo XVI. ${ }^{25}$ En 1501, por solicitud de los representantes de Navalmoral, los soberanos se dirigen al corregidor reprochando la falta de ejecución de las sentencias. Santiesteban había visitado los términos y adjudicado al lugar lo que les pertenecía "avido respeto a la poblaçión e vezinos dél, e a su nes\#esidad que toviese para sus ganados e avido respeto con los otros lugares de la tierra de esa dicha çibdad” (López Villalba, 2004, 132: 298). A pesar de esto, la aldea nunca encuentra justicia y sus procuradores denuncian la connivencia de Pedro con el resto de los regidores: "por el favor que el dicho Pedro de Ávila tiene en la dicha çibdad, diz que ningund regidor la ha conplido e diz que busca escusa\#iones por evadirse e asý el dicho lugar de Navalmoral nunca ha podido alcançar conplimiento de lo que por nos fe mandado" (López Villalba, 2004, 132: 298).

Pese a la existencia de sentencias a su favor, varios vecinos solicitan seguro a los reyes porque temen las represalias de Pedro y de otros poderosos. Los Reyes Católicos otorgan el seguro, señalando las acciones violentas y abusivas que realiza Pedro Dávila junto a sus hombres y criados:

\begin{abstract}
"tomamos e reçebimos a los dichos Gil Fernández e Andrés Garçía e a sus mugeres e fijos e criados, onbres e criados, e otras personas quel nonbrare e declarare por sus nonbres ante vos, las dichas nuestras justiçias, o ante qualquier de vos, so nuestra guarda e seguro e anparo e defendimiento real. E lo aseguramos del dicho Pedro de Ávila e de sus onbres e criados, e de otras personas e cavalleros qualesquier de quien dixeren que se themen e reçelan, que los non maten nin lisyen nin prenden nin prendan nin fagan otro mal nin daño nin desaguisado alguno en sus personas e bienes contra razón e derecho conmo non devan" (Canales Sánchez, 1996, 50: 119). ${ }^{26}$
\end{abstract}

A pesar de las cartas obtenidas, los pecheros se sienten igualmente inseguros. La apropiación de tierras implica también el despliegue de violencia física, que encierra la posibilidad de la muerte.

Como hemos visto hasta aquí, ante las distintas acciones señorializadoras llevadas adelante por las elites regimentales -ocupación de tierras, imposición de prendas y tributos, uso de la fuerza, avance sobre suelos a partir de posesiones legítimas-, en este caso del linaje de los Dávila, los campesinos responden también apelando a una diversidad de estrategias, apoyándose en los canales formales previstos por la monarquía y en sus propias instancias políticas de representación. Los casos de señorializaciones son seguidos atentamente por los procuradores, quienes permanentemente insisten en la restitución efectiva de sus bienes y la restauración de sus prácticas agrarias.

De este modo, los aldeanos manifiestan su descontento no sólo cuando se registra un aumento del tributo o una modificación de la costumbre, sino cuando son violentadas sus condiciones de existencia en un sentido mucho más amplio; de allí que incluyamos en ellas a su propia organización política. La profusa documentación abulense revela que las prácticas coactivas que afectan sus estructuras políticas generan un malestar entre los tributarios que se plasma en sucesivas demandas. En este sentido, destacan las acciones violentas de Gil González de Ávila sobre los aldeanos de Bóveda y sus organizaciones políticas.

El conflicto se origina en las diversas usurpaciones que lleva a cabo este regidor, que afectan particularmente al concejo rural (Luis López, 1995, 46: 152). Frente al reclamo de los hombres de la tierra, el caballero se involucra directamente en atacar a sus rivales, violentando a los oficiales aldeanos: "el dicho Gil Goncález e sus fijos e criados, por su mandado...les avían fecho e fazían muchas ynjurias e fuerças ey males al dicho conçejo e 
personas partyculares dél” (García Pérez, 1998, 46: 85). Entre las acciones de Gil González denunciadas por el "conçejo, alcaldes, alguazyl, regidores, ofiçiales e omes buenos del lugar de Vóbeda" (García Pérez, 1998, 46: 85$)^{27}$ se encuentra el avasallamiento del concejo rural:

"el dicho Gil Gonçález de Avila fazía a los dichos sus partes muchos males e daños y entrava en conçejo estando los dichos sus partes juntos y les estorvava lo que querían hazer que estava bien al dicho concejo, e non sonsyntía a hazer otra cosa sy non lo que él quería, y a los que ge lo contradecían los ynjuriava de palabra y de fecho" (García Pérez, 1998, 46: 85-86).

Evidentemente, las organizaciones propias de los pecheros y su capacidad de generar múltiples demandas resultan una molestia para los miembros de las elites regimentales que pretenden disponer del dominio sobre los pobladores; al punto que en ciertas circunstancias no dudan en recurrir a la fuerza para impedir las reuniones. En este sentido, la acción política de la tierra incide en las condiciones de reproducción de los aldeanos; de manera que todo intento de los poderosos por cercenarla amerita la misma resistencia que la que ocasiona la alteración de los usos y aprovechamientos agrarios.

\section{Conclusiones}

A lo largo de estas páginas hemos analizado una serie de conductas coactivas desplegadas por algunos miembros de la elite regimental de Ávila sobre los productores durante el siglo XV, con el objetivo de arribar a una caracterización del significado de las mismas. Estamos en presencia de prácticas que por sus efectores y sus consecuencias pueden ser consideradas de tipo señorial. La detracción de la justicia concejil, la imposición de un poder de mando particular y la extracción privada de excedente que resulta de las diversas coacciones estudiadas permiten sostener esta interpretación. La ausencia de reconocimiento jurídico, o más aún, su abierto enfrentamiento con los soberanos, impide que estas situaciones concluyan en el desgajamiento formal del realengo y la creación de un señorío privado. Se trata por tanto, de prácticas señorializadoras que se originan dentro del realengo. Éstas implican poder político y jurisdiccional sobre la población y nos informan tanto acerca de las cualidades sustanciales de las elites, como del vínculo que las une con los tributarios.

Si la incorporación de concejos enteros de villa y tierra por parte de las grandes casas nobiliarias constituye un fenómeno de relevancia ampliamente estudiado, la presencia de "prácticas señorializadoras" realizadas por sectores de las oligarquías urbanas y miembros de la baja nobleza local, configura un problema de sustancial interés. Las masivas actuaciones de personajes encumbrados de las elites locales que conducen a las sistemáticas usurpaciones de términos concejiles, la imposición de prendas y de tributos en un escenario regular de violencia señorial conforman un fenómeno ineludible que quisimos destacar en este trabajo. El examen detenido de estas sistemáticas coacciones retrata a las comunidades pecheras que permanecen en la jurisdicción del realengo, sometidas también a lógicas de tipo señorial. Las presiones y abusos que padecen los colectivos campesinos y que alteran sus pautas de reproducción consuetudinarias deben entenderse a su vez desde la condición de quienes los llevan a cabo. No sólo se trata de propietarios privilegiados, caballeros de alto rango -en muchos casos con estrechos lazos con la propia monarquía- sino que en la mayoría de los casos estamos ante miembros encumbrados de la elite dirigente concejil; es decir que, quienes menoscaban a los contribuyentes y con ello al imperio jurisdiccional de los soberanos, son al mismo tiempo quienes ejercen el poder político regimental, en el marco del realengo transferido.

Los campesinos abulenses conviven cotidianamente con este tipo de prácticas, que señalan el carácter señorial de las relaciones de dominación en el feudalismo tardío, sea cual fuere el ámbito jurisdiccional en el que habiten. Para concluir, consideramos pertinente la afirmación de López-Guadalupe Pallarés: "La presentación entre el realengo y el señorío como dos opciones jurisdiccionales opuestas; una benévola, la otra perjudicial; una moderna, la otra arcaica; una ciudadana, la otra servil; son una construcción ideológica romántica, que opera con apriorismos...” (López- Guadalupe Pallarés, 2018: 445). 
La comparación de estas acciones de hecho perpetradas por las oligarquías urbanas, con la constitución de señoríos que alcanzan el reconocimiento legal de la Corona será objeto de futuras investigaciones. Se trata en última instancia de profundizar el conocimiento respecto de la efectiva incidencia de los encuadramientos jurisdiccionales en la reproducción de las comunidades pecheras castellanas.

\section{BibLIOGRAFía}

Astarita, C. (1994). "Caracterización económica de los caballeros villanos de la Extremadura castellano-leonesa. Siglos XII-XV”. Anales de historia antigua y medieval, 27, pp. 11-84.

Astarita, C. (2000). “¿Tuvo conciencia de clase el campesinado medieval?”. Edad Media: revista de historia, 3, pp. 89-114.

Barrios García, A. (1983-1984). Estructuras agrarias y de poder en Castilla: El ejemplo de Ávila (1085-1320) 2 vol. Salamanca: Ediciones Universidad de Salamanca.

Bonachía Hernando, J. A., Martín Cea, J. C. (1998). "Oligarquías y poderes concejiles en la Castilla bajomedieval: Balances y perspectivas”. Revista d'historia medieval, 9, pp. 17-40.

Bourdieu, P. (2006). Campo del poder y reproducción social. Elementos para un análisis de la dinámica de las clases. Córdoba: Ferreyra Editor.

Clemente Ramos, J. (1991). "Estructura concejil y sociedad feudal, en la transierra extremeña siglos XII y XIII". Hispania. Revista española de historia, 177(51), pp. 41-71.

Colombo, O. (2018). "Formas de propiedad privilegiada y conflictos sociales en el sistema concejil castellano (Ávila, siglo XV)”. En C. Luchía (coord.). Comunidades en conflicto. Buenos Aires: Ed. FyL, Colección Saberes, pp. 175-206.

Estepa Díez, C. (1984). "El alfoz y las relaciones campo-ciudad en Castilla y León durante los siglos IX al XII”. En la España medieval, 2, pp. 7-26.

F. Foronda, F., A. I. Carrasco Manchado (Coords.) (2008). El contrato politico en la Corona de Castilla: cultura y sociedad politica entre los siglos Xy XVI. Madrid: Dykinson.

Freedman, P. (2000). "La resistencia campesina y la historiografía de la Europa medieval". Edad Media: revista de historia, 3, pp. 17-38.

García Oliva, M. D. (2018). "Señores contra campesinos: un conflicto por la tierra en Mirabel a fines de la Edad Media y principios de los Tiempos Modernos (1488-c. 1520)”. Espacio, tiempo y forma. Serie III. Historia Medieval, 31, pp. 303-342.

Guerrero Navarrete, Y. (1998). "Elites urbanas en el siglo XV: Burgos y Cuenca”. Revista d'historia medieval, 9, pp. 81-104.

Jara Fuente, J. A. (2002-2003). “'Que memoria de onbre non es en contrario'. Usurpación de tierras y manipulación del pasado en la Castilla urbana del siglo XV”. Studia Historica. Historia Medieval, 21 (20), pp. 73-103.

Jara Fuente, J. A. (2007). “Estructuras formales de poder y de organización de las clases dominantes urbanas en Castilla. El Regimiento: una crisis del siglo XIV en el siglo XV”. Edad Media, 8, pp. 225-241.

López Benito, C. I. (1983). “Usurpaciones de bienes concejiles en Salamanca durante el reinado de los Reyes Católicos”. Studia Historica. Historia Moderna, 1, pp. 169-184.

López-Guadalupe Pallarés, M. J. (2018). "Procesos de señorialización en concejos de realengo en la Extremadura castellano-leonesa. Un estado de la cuestión”. Espacio, tiempo y forma. Serie III. Historia medieval, 31, pp. 431-454.

Lorenzo Cadarso, P. (1996). Los conflictos populares en Castilla (siglos XVI-XVII). Madrid: Siglo XXI.

Luchía, C. (2016). "Regidores en conflicto: pertenencia estamental, trayectorias individuales y estrategias de poder de las elites regimentales castellanas en el siglo XV”. Magallánica: revista de historia moderna, 5, pp. 123-148. 
Luis López, C. (1993). “Presentación”. En Luis López, C. Documentación Medieval de los Archivos Municipales de La Andrada, Candeleda, Higuera de las Dueñas y Sotillo de Andrada. Ávila: Ediciones de la Obra Cultural de la Caja de Ahorros de Ávila.

Martín Romera, M. A. (2014). “《Como sy fuesen vuestros vasallos »: las relaciones informales de las oligarquías urbanas y el sometimiento del territorio en la Castilla bajomedieval". Edad media: revista de historia, 15, pp. 155-174.

Mínguez Fernández, J. M. (1980). "La resistencia antiseñorial del concejo de Cáceres durante el siglo XV: Un esquema para el análisis de las minorías dirigentes de los concejos”. Norba. Revista de arte, geografía e historia, 1, pp. 219-230.

Mínguez Fernández, J. M. (1982). "Feudalismo y concejos: Aproximación metodológica al análisis de las relaciones sociales de los concejos medievales castellano-leoneses". En la España medieval, 3, pp. 109-122.

Monsalvo Antón, J. M. (1986). "Poder político y aparatos de estado en la Castilla bajomedieval. Consideraciones sobre su problemática”. Studia Historica. Historia Medieval, 4, pp. 101-169.

Monsalvo Antón, J. M. (1988). El Sistema Político Concejil: el ejemplo del señorio medieval de Alba de Tormesy su concejo de villa y tierra. Salamanca: Ediciones Universidad de Salamanca.

Monsalvo Antón, J. M. (1989). "La participación política de los pecheros en los municipios castellanos de la Baja Edad Media. Aspectos organizativos”. Studia Historica. Historia Medieval, 7, pp. 37-93.

Monsalvo Antón, J. M. (1992a). "Concejos castellano-leoneses y feudalismo (siglos XI- XIII): Reflexiones para un estado de la cuestión”. Studia Historica. Historia Medieval, 10, pp. 203-243.

Monsalvo Antón, J. M. (1992b). "Paisaje agrario, régimen de aprovechamientos y cambio de propiedad en una aldea de la tierra de Ávila durante el siglo XV. La creación del término redondo de Zapardiel de Serrezuela". Cuadernos Abulenses, 17, pp. 11-110.

Monsalvo Antón, J. M. (1997). "Las dos escalas de la señorialización nobiliaria al sur del Duero: concejos de villa y tierra frente a la señorialización menor (Estudio a partir de casos del sector occidental: señoríos abulenses y salmantinos)". Revista d'historia medieval, 8, p. 275-338.

Monsalvo Antón, J. M. (2001). “Usurpaciones de comunales: conflicto social y disputa legal en Ávila y su tierra durante la Baja Edad Media”. Noticiario de historia agraria, 24, pp. 89-122.

Monsalvo Antón, J. M. (2006). "El Realengo abulense y sus estructuras de poder durante la Baja Edad Media". En VV.AA. Historia de Ávila, Tomo III, La Baja Edad Media (Siglos XIV y XV). Ávila: Ediciones de la Institución "Gran Duque de Alba", pp. 70-172.

Monsalvo Antón, J. M. (2010). "Raíces sociales de los valores estamentales concejiles: la construcción de las mentalidades y culturas rurales de caballeros y pecheros (Ávila y su tierra, siglos XIII-XV)". En Comunalismo concejil abulense. Paisajes agrarios, conflictos y percepciones del espacio rural en la Tierra de Ávila y otros concejos medievales. Ávila: Diputación de Ávila. Ediciones de la Institución “Gran Duque de Alba”, pp. 359-421.

Monsalvo Antón, J. M. (2012). "Pobladores, caballeros, pecheros y señores. Conflictos sociales en el concejo de Ávila. (ss. XI-XV)”. En F. García Fitz, J. F. Jiménez Alcázar (Coords.). La Historia peninsular en los espacios de frontera: las "extremaduras históricas" y la "transierra" (S. XI-XV). Madrid: Sociedad Española de Estudios Medievales, pp. 375-426.

Monsalvo Antón, J. M. (2015-2016). “Arraigo territorial de las grandes casas señoriales (infantes de Aragón, Alba, Estúñiga y Alburquerque) en la cuenca suroccidental del Duero en el contexto de la pugna « nobleza-monarquía »". Anales de la Universidad de Alicante. Historia Medieval, 19, pp. 99-152.

Moreno Núñez, J. I. (1982). “Los Dávila, linaje de caballeros abulenses”. En la España Medieval, 3, pp. 157-172.

Muñoz Gómez, V. (2009). “Administración señorial y gobierno urbano durante los primeros Trastámara. Los corregidores del infante Fernando de Antequera y Leonor de Alburquerque (1392-1421)”. En J. F. Jiménez Alcázar, J. Maíz Chacón, C. Villanueva Morte, I. Calderón Medina (Eds. Científicos). Actas IV simposio internacional de jóvenes medievalistas. Murcia: Ligia Comunicación y Tecnología, pp. 161-186.

Sánchez Albornoz, C. (1956). España, un enigma histórico 2 vols. Buenos Aires: Editorial Sudamericana. 


\section{Fuentes}

Canales Sánchez, J. A. (1996). Documentación Medieval Abulense en el Registro General del Sello Vol. VI. Ávila: Ediciones de la Institución "Gran Duque de Alba".

Casado Quintanilla, B. (1999). Documentación del Archivo Municipal de Ávila Vol. IV. Ávila: Ediciones de la Institución "Gran Duque de Alba".

García Pérez, J. J. (1998). Documentación Medieval Abulense en el Registro General del Sello Vol. XVI. Ávila: Ediciones de la Institución "Gran Duque de Alba".

López Villalba, J. M. (2004). Documentación Medieval Abulense en el Registro General del Sello Vol. XVII. Ávila: Ediciones de la Institución "Gran Duque de Alba".

Luis López, C. (1995). Documentación Medieval Abulense en el Registro General del Sello Vol. VIII. Ávila: Ediciones de la Institución "Gran Duque de Alba".

Martín Rodríguez, J. L. (1995). Documentación Medieval Abulense en el Registro General del Sello Vol. I. Ávila: Ediciones de la Institución "Gran Duque de Alba".

\section{Notas}

1. En Ávila, esta nueva arquitectura institucional del regimiento puede constatarse para mediados del siglo XIV, específicamente en 1345 ya hay referencias a la existencia de individuos encargados de "ver e hordenar la fazienda e los fechos de conçejo” (Monsalvo Antón, 1988: 155). La composición del regimiento se modifica a lo largo de su historia. En el siglo XV son catorce los regidores que lo integran, de cargos vitalicios y hereditarios, destacándose dos de sus miembros como cabezas de los dos linajes más importantes: Pedro Dávila, del linaje de San Juan, y Gonzalo Dávila (sucedido por Hernán Gómez Dávila), del de San Vicente. Es por ello que Monsalvo Antón señala que el regimiento se compone de "dos más doce" regidores, distinguiendo a los regidores eminentes del resto de los oficiales (Monsalvo Antón, 2006: 91). Son numerosas las contribuciones respecto de las elites que ejercen posiciones preeminentes en los concejos que tienden a considerar la existencia de una minoría diferenciada devenida en patriciado urbano (Guerrero Navarrete, 1998; Jara Fuente, 2007; Luchía, 2016; Martín Cea y Bonachía Hernando, 1998). "No se trata ya sólo de que estos destacados personajes pertenecieran en cuanto al estatuto fiscal o jurídico a los privilegiados caballeros exentos, sino que como minoría conspicua dentro del dicho estrato jurídico, empezaba a fraguar una determinada fisonomía de elite social restringida que denominamos patriciado urbano" (Monsalvo Antón, 2010: 373).

2. Se trata de la década en la cual se reformulan las teorías y se refutan, en palabras de Monsalvo Antón, los “clichés sobre los concejos democráticos castellanos y sus presuntos hombres libres e iguales” (Monsalvo Antón, 1992a: 203).

3. "no puede asimilarse, y esto es lo principal, la condición individual como señores de que disfrutaron algunos dirigentes urbanos con el hecho de que la caballería concejil fuera una "clase señorial" en su conjunto que explotaba colectivamente al campesinado concejil a través del concejo, que es como interpretó la sociedad concejil plenomedieval cierto sector del medievalismo" (Monsalvo Antón, 2012: 394).

4. Sin embargo, esta caracterización hegemónica durante mucho tiempo, está empezando a ser matizada. Al respecto, Colombo (2018).

5. "los caballeros usurpadores actuaban a través de "sus hombres", mayordomos de sus propiedades, sus criados, sus apaniaguados, hombres armados a veces...en definitiva, extensas y remotas redes clientelares que...debían suponer la ominosa evidencia de que esos antagonistas poderosos, caballeros arrogantes, que se apropiaban de los bosques, la hierba o las aguas de los pueblos, formaban una tela de araña de dimensiones desconocidas y descomunales contra la que era difícil luchar" (Monsalvo Antón, 2001: 105).

6. "[Las violencias] Se parecen a los abusos señoriales, pero no lo eran en rigor. Algunos historiadores confunden a veces estos fenómenos, con la misma torpeza con la que otros, al ver en las fuentes la palabra señor de un lugar, han pensado que había señorío, cuando a menudo a lo que se refería ese término será simplemente a la propiedad de término redondo, pero sin haber alcanzado la jurisdicción del mismo" (Monsalvo Antón, 2012: 420).

7. El destacado es nuestro.

8. Aunque a partir de la plataforma que significaba la propiedad previa y la combinación de usurpaciones y acciones ilegítimas, es común que se usurpe la jurisdicción de un lugar y se produzca la señorialización (legal, reconocida por la monarquía).

9. "Es cierto que los campesinos no son sus vasallos, pero también es cierto que los caballeros los someten y sojuzgan, en ocasiones durante décadas, como si lo fueran" (Colombo, 2018: 179). 
10. La capacidad política de los tributarios en la Edad Media es objeto de amplia reflexión y debate. Por mucho tiempo la historiografía ha negado al estamento no privilegiado su carácter de sujeto político. Según estas visiones, el campesinado sería un sector pasivo, que en el mejor de los casos "reaccionaría" frente a situaciones puntuales de ataque a sus intereses inmediatos, como podría ser el aumento particular de un tributo y la modificación de la costumbre en general. Rodney Hilton, Jaques Le Goff, Robert Fossier, entre otros medievalistas, son parte de esta tradición. Al respecto, Astarita (2000); García Oliva (2018); Freedman (2000). En el caso de los concejos castellanos bajomedievales, Monsalvo Antón abre un nuevo panorama para los medievalistas al sostener que a pesar de la exclusión formal de los pecheros de los órganos de gobierno, éstos intervienen en política, llevan a cabo una destacada lucha en defensa de sus intereses y obtienen importantes reivindicaciones (Monsalvo Antón, 1989). En este sentido, este autor afirma que en Ávila: "los pecheros consiguieron ser una estimable fuerza política en la sociedad concejil, aun sin estar presentes en el staff decisorio del Regimiento" (Monsalvo Antón, 2006: 164).

Para encauzar sus demandas, los pecheros construyen múltiples organizaciones -algunas específicas de la tierra, otras de la ciudad y otras generales de la comunidad de villa y tierra-; a la vez que existen representantes del estamento en distintas instancias. Especialmente los asuntos fiscales y la regulación del espacio concentran la preocupación de los pecheros en sus reuniones asamblearias. A su vez, los sexmeros, el procurador de la ciudad, así como el procurador general de los pecheros, asisten en ocasiones en el siglo XV a las sesiones del regimiento. Si bien no pueden participar activamente en las decisiones políticas, ya que carecen de voz y voto en el concejo, y su presencia no es regular, suelen hacer uso de la palabra en lo que respecta a temas que afecten directamente sus intereses. De este modo, la propia noción de un regimiento cerrado y de un ejercicio exclusivista del poder debe ser matizada a la luz de estas consideraciones. Para un análisis más exhaustivo de la cuestión ver Monsalvo Antón (1989; 2006). El recurso que utilizan los tributarios para hacer valer sus intereses es la vía judicial. En este sentido, los canales formales provistos por la monarquía conforman el principal medio a partir del cual se procesa el conflicto (Monsalvo Antón, 2001). De todas formas, se documentan procesos de violencia abierta, generalmente cuando las vías legales no dan respuesta (García Oliva, 2018).

11. El establecimiento de la autoridad señorial se impone sobre estructuras institucionales abigarradas, conformadas por "elites locales celosas de su preeminencia social, política y económica” (Muñoz Gómez, 2009: 162). Para el caso de Cáceres, Mínguez Fernández destaca que su concejo lleva a cabo una oposición "respetuosa pero enérgica” (Mínguez Fernández, 1980: 223) a la señorialización. El marco organizativo del concejo urbano facilita el mayor grado de resistencia, por más que finalmente se lleva a cabo la señorialización.

12. "las noblezas urbanas lograron señoríos más modestos, a veces de único lugar convertido en villa para sí o con unas pocas aldehuelas; no hubo resistencia que no fuera legal frente a los nuevos señoríos” (Monsalvo Antón, 2012: 419).

13. "el señor fue aceptado como tal sin ninguna contradicción, y (...) los vecinos le obedecieron y besaron la mano cuando tomó posesión del lugar" (García Oliva, 2018: 312). Al respecto, destaca Miguel López-Guadalupe Pallarés: "De otra forma, la señorialización podría seguir interpretándose desde el prejuicio tradicional, como un cambio jurisdiccional que casi necesariamente perjudicaba a la población y que comportaba el empeoramiento de las condiciones materiales de los vecinos. Bajo esta perspectiva, y aunque así pudiera ser en algunos casos, no se comprenden los procesos de señorialización que no presentan ningún tipo de resistencia y se generalizan al final del medievo castellano" (López-Guadalupe Pallarés, 2018: 445).

14. El linaje de los Dávila se agrupa en distintas familias o casas. Es así que encontramos la casa de Villatoro, señores de esta villa y de Navamorcuende; la Casa de Villanueva y San Román; los Dávila de la Casa de Cespedosa, titulares del señorío de Cespedosa y Puente de Congosto y los Dávila-Casa de las Navas. Descendientes de Esteban Domingo, quien había sido compensado por Alfonso XI por sus múltiples servicios en la guerra contra los musulmanes, los Dávila logran apoderarse de varias villas y términos, y acceden para el siglo XVI a la alta nobleza bajo el título de marqueses de Las Navas (Moreno Núñez, 1982).

15. Monsalvo ha analizado ampliamente el miedo que testimonian los aldeanos en sus declaraciones (Monsalvo Antón, 2006).

16. Luchía reconoce esta doble faceta que caracteriza a los regidores: desde sus cargos políticos se involucran en la defensa de los términos de la ciudad, mientras que al mismo tiempo participan de las apropiaciones (Luchía, 2016).

17. El concejo aldeano ha ganado sentencias que determinan que posee "por suyos e conmo suyos los términos e prados e pastos e montes e exidos e abrevaderos del dicho lugar” (Canales Sánchez, 1996, 3: 14).

18. El destacado es nuestro. Gil González de Ávila, otro regidor abulense, también impone prendas y exhibe acciones compulsivas similares en la aldea de Bóveda, a partir de la apropiación de la dehesa de Rialmar "que en tiempo ynmemorial a esta parte el dicho conçejo avía tenido e poseído por suya e conmo suya” (García Pérez, 1998, 46: 89). Sin embargo, Gil González violenta los usos "paçiéndola e comiéndola e prendando della a los forasteros, syn que parte alguna toviese el dicho Gil Gonçález" (García Pérez, 1998, 46: 89). Al ocupar las tierras "faziendo fuerças a los dichos sus partes se llamava señor de cierta parte de la dicha dehesa e fazía prendas a los vezinos del dicho lugar” (García Pérez, 1998, 46: 89). El destacado es nuestro. 
19. De hecho, señala su arrepentimiento por dar falso testimonio, impulsado por el miedo: "e que agora se arrepiente porque no se lo dixo allí a Cogollos, que si él supiera que tan ayna uviera de venir aquí el corregidor que, aunque le tovieran ocho días en la cadena, él lo quisiera aver dicho" (Casado Quintanilla, 1999, 356: 84).

20. El destacado es nuestro.

21. "en cunpliéndolas e esecutándolas, defendáis e anparéys al dicho lugar e a los vezinos e moradores dél e en los dichos términos, segund e conmo la dicha ley lo dispone" (Martín Rodríguez, 1995, 51: 125). En la intervención de los Reyes Católicos respecto de la ocupación y la imposición de penas que realiza Pedro Dávila en el lugar de Burgohondo, también se ordena que se ejecuten las sentencias atendiendo a la ley de las Cortes de Toledo "que fabla sobre razón de los términos ocupados a las çibdades e villas e logares de los nuestros reynos e señoríos, cunpláys e executéys las dichas vuestras senten\#ias e mandamientos; e, en cunpliéndolas e executándolas, defendáis e anparéys al dicho logar e vezinos dél..." (Canales Sánchez, 1996, 5: 18).

22. El lugar de Burgohondo señala que Santiesteban "les ovo tornado e restituydo por su senten\#ia, segund la forma de la ley por nos fecha en las Cortes de Toledo, çiertos términos que Pedro de Ávila e sus mayordomos e fautores les tenían tomados e ocupados de lo común de la çibdad de Ávila e del dicho logar del Burgo..." (Canales Sánchez, 1996, 8: 22). Al respecto también ver Canales Sánchez (1996, 13: 29-30; 53: 124).

23. A pesar de la restitución de términos al concejo de Navalmoral, "después el dicho Pedro de Ávyla ha inquietado e molestado, e otros por su mandado, aviéndolo el por rato e grato, a los vezinos e moradores de la dicha çibdad e su tierra e Nabalmoral e Nabalendrinal e Navalcarros en la posesión de los dichos términos, prendándolos por los dichos términos... Faziéndoles fazer renta por ellos e usurpando la juredi\#ión de la dicha çibdad...." (Canales Sánchez, 1996, 49: 112-113).

24. Señalan los reyes: "E que por vos fue senten\#iado la dicha dehesa por límites que va" (Canales Sánchez, 1996, 8: 22).

25. La demora en la resolución del pleito permite observar los límites de los procedimientos formales de justicia para proteger el patrimonio de las comunidades.

26. El destacado es nuestro. En el seguro real dado contra Gil González de Ávila se reitera una fórmula similar: "E los aseguramos de los dichos Gil Gonçález de Avila e de sus fijos e criados e parientes e amigos e valedores e de otras qualesquier personas que por ellos han de hazer...para que les non fieran nin maten nin lisien nin prendan nin les fagan nin manden fazer, de derecho nin de fecho, otros ningunos males nin daños nin desaguisados algunos en sus personas nin en sus bienes, injusta e non debidamente, contra razón e derecho" (Luis López, 1993, 3: 39).

27. También destaca el accionar violento del hijo de Gil González, del mismo nombre, que desde hace tres años "que syn cabsa e syn razón alguna dió una cuchillada a un Alonso del Río e otra a su muger, de Juan Ximénez, vezyno del dicho lugar" (García Pérez, 1998, 46: 85). 